\title{
Lyonel Trouillot, Yanvalou pour Charlie
}

\section{Alba Pessini}

\section{OpenEdition}

\section{Journals}

\section{Édition électronique}

URL : http://journals.openedition.org/studifrancesi/7066

DOI : 10.4000/studifrancesi.7066

ISSN : 2427-5856

\section{Éditeur}

Rosenberg \& Sellier

\section{Édition imprimée}

Date de publication : 1 septembre 2010

Pagination : 418-419

ISSN : 0039-2944

\section{Référence électronique}

Alba Pessini, « Lyonel Trouillot, Yanvalou pour Charlie», Studi Francesi [En ligne], 161 (LIV | II) | 2010, mis en ligne le 30 novembre 2015, consulté le 13 janvier 2021. URL : http://journals.openedition.org/ studifrancesi/7066 ; DOI : https://doi.org/10.4000/studifrancesi.7066

\section{Ce document a été généré automatiquement le 13 janvier 2021.}

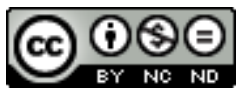

Studi Francesi è distribuita con Licenza Creative Commons Attribuzione - Non commerciale - Non opere derivate 4.0 Internazionale. 


\title{
Lyonel Trouillot, Yanvalou pour Charlie
}

\author{
Alba Pessini
}

\section{RÉFÉRENCE}

LYONEL TROUILLOT, Yanvalou pour Charlie, Arles, Actes Sud, 2009, pp. 175.

1 Les lecteurs assidus de Lyonel Trouillot le savent, ouvrir un de ses romans c'est décider et accepter d'entrer dans l'univers haïtien, dans une société haïtienne contemporaine qui nous est présentée sans filtre et sans masque, c'est aussi accepter la rencontre avec des existences dont le destin n'est jamais banal et qui racontent toutes, à leur manière, ce que vivre en Haïti aujourd'hui veut dire. Une fois encore, la difficile réalité haïtienne frappe le lecteur, le contraint à se plonger dans un réel fait de détresse, de misères morale et spirituelle, de folie aussi. Toutefois la force de l'écriture de Trouillot ne trouve pas ses racines dans un pacte de restitution du réel, le réel de ses histoires prend à la gorge, mais dépasse bien souvent la simple représentation de ce qui est. Dans Yanvalou pour Charlie aussi, grâce auquel l'auteur a obtenu le prix littéraire Wepler La Poste en novembre 2009, nous retrouvons les constantes de son œuvre. La majeur partie du roman se situe dans une ville dont les banlieues qui la cernent sont décrites sans aucune complaisance et met en scène un personnage principal, Mathurin, qui, venu de sa campagne qu'il renie (tout comme il cache son deuxième prénom Dieutor qui dénonce ses origines rurales), a entrepris de gravir les échelons pourris d'une société où le mensonge et la corruption dominent. Jeune avocat voué à une brillante carrière, sa vie est programmée pour une réussite d'où les sentiments, la bonté et la générosité sont bannis. Cette planification sera toutefois bouleversée par l'entrée en scène d'un jeune adolescent, Charlie, qui, comme un ange noir, pénètre dans son élégant bureau pour lui rappeler les laideurs de son passé, les déchirures de son enfance, les morts de sa famille et ses amours d'antan qu'il a sacrifiés sur l'autel du succès. Avec Charlie entrent dans le roman une série de personnages des marges, des jeunes surtout qui, comme Charlie, logent dans une structure humanitaire et religieuse 
qui s'est fixé le but de les arracher à la rue. Ce microcosme, une espèce de Cour des Miracles entre quatre murs, qui voudrait être un lieu de protection ne fait en réalité que ramasser et accueillir ceux qui habitaient les trottoirs. Maladies, déformations physiques, morts prématurées, drames de l'adolescence, guerres que se livrent les jeunes entre eux sont le lot quotidien de cette œuvre de «bienfaisance». Dans ce roman où Trouillot alterne les voix de quatre narrateurs pour nous raconter sa vérité, qui ne craint pas d'égratigner au passage bien des lieux communs, s'élèvent, malgré tout, des raisons d'espérer là où on les attendrait le moins et sous des formes qui ne manquent pas d'être ironiques. Mathurin ne sortira pas indemne de sa rencontre avec Charlie, le roman est bien l'histoire de la transformation de ce personnage à travers lequel le lecteur voit défiler toutes les contradictions de la terre haïtienne: richesse et misère, beaux quartiers et taudis, passion et cynisme. Inlassablement, d'un roman à l'autre, Lyonel Trouillot nous convie à regarder, au-delà de la violence des rapports humains, au-delà d'un contexte âpre et difficile, les mains tendues qui constituent un réseau, une toile, que le lecteur voit se dessiner au fil des pages. 